Pesq. Vet. Bras. 29(1):83-88, janeiro 2009

\title{
Mannheimiose pulmonar experimental em bezerros: swab nasal e nasofaringeano como auxílio diagnóstico ${ }^{1}$
}

\author{
Adriana de Souza Coutinho ${ }^{2}$, José Paes de Oliveira Filho ${ }^{3^{*}}$, Daniel Pessoa \\ Gomes da Silva ${ }^{3}$, Andreza Pimenta de Oliveira ${ }^{3}$, Júlio Simões Marcondes ${ }^{3}$, \\ Simone Biagio Chiacchio ${ }^{3}$, Antônio Carlos Paes ${ }^{4}$, Amanda Keller Siqueira ${ }^{4}$, \\ Rogério Martins Amorim ${ }^{3}$ e Roberto Calderon Gonçalves ${ }^{3}$
}

\begin{abstract}
Coutinho A.S., Oliveira Filho J.P., Silva D.P.G.S., Oliveira A.P., Marcondes J.S., Chiacchio S.B., Paes A.C., Amorim R.M. \& Gonçalves R.C. 2009. [Experimental pneumonic mannheimiosis in calves: Nasal and nasopharingeal swabs for diagnostic.] Mannheimiose pulmonar experimental em bezerros: swab nasal e nasofaringeano como auxílio diagnóstico. Pesquisa Veterinária Brasileira 29(1):83-88. Departamento de Clínica Veterinária, Faculdade de Medicina Veterinária e Zootecnia, Universidade Estadual Paulista, Campus de Botucatu, Distrito de Rubião Júnior s/n, Botucatu, SP 18618000, Brazil. E-mail: zep.filho@ hotmail.com

An experimental model of bovine pneumonic mannheimiosis (BPM) was used to evaluate the nasal and nasopharynx bacterial species of calves during the course of the disease and for checking the diagnostic efficiency of nasal swab (NS) and nasopharingeal swab (NPS) microbiological exams. A total of 28 calves were randomized into four experimental groups (G1-G4). NS and NPS were obtained 7 days before and 12 (G1), 24 (G2), 48 (G3) e 72 (G4) hours after intrabronchial inoculation of Mannheimia haemolytica. After the induction of BPM, M. haemolytica biotype A was the predominant isolated bacterium in NS and NPS in all evaluated sampling times, except for one NS (harvested 24 hours). There were no significant statistical differences for the rates of Pasteurella multocida isolation in NS and NPS, harvested before and after the induction of BPM. However, this bacterium was isolated more frequently after the induction of BPM, mainly in NPS. Therefore, the microbiological NS and NPS exams were important auxiliary tests for diagnosing BPM.
\end{abstract}

INDEX TERMS: Bacterial flora, upper airway, respiratory diseases, bovine, Mannheimia haemolytica.

RESUMO.- Um modelo experimental de mannheimiose pneumônica bovina (MPB) foi utilizado com o objetivo de avaliar as espécies bacterianas das cavidades nasais e nasofaringeanas em diferentes momentos do curso da

\footnotetext{
${ }^{1}$ Recebido em 25 de março de 2008.

Aceito para publicação em 23 de setembro de 2008.

Parte da Tese do primeiro autor, apresentada no Programa de PósGraduação em Medicina Veterinária, Faculdade de Medicina Veterinária e Zootecnia (FMVZ), Universidade Estadual Paulista (Unesp), Campus de Botucatu.

2 Departamento de Medicina Veterinária. Universidade Federal de Lavras, Campus Universitário, Cx. Postal 37, Lavras, MG 37200-000, Brasil. E-mail: adriscou@ufla.br

${ }^{3}$ Departamento de Clínica Veterinária, FMVZ, Unesp-Botucatu, Distrito de Rubião Júnior s/n, Botucatu, SP 18618000 , Brasil. *Autor para correspondência: zep.filho@ hotmail.com

${ }^{4}$ Departamento de Higiene Veterinária e Saúde Pública, FMVZ, UnespBotucatu. E-mail: paesacmi@fmvz.unesp.br
}

doença, bem como verificar a eficiência diagnóstica do exame microbiológico dos swabs nasais (SN) e nasofaringeanos (SNF). Um total de 28 bezerros foi distribuído aleatoriamente em quatro grupos experimentais (G1 a G4). SN e SNF foram colhidos sete dias antes e 12 (G1), 24 (G2), 48 (G3) e 72 (G4) horas após a inoculação intrabronquial de Mannheimia haemolytica. Após a indução da MPB, a bactéria $M$. haemolytica biotipo A foi predominante nos SN e SNF, sendo isolada em todos os momentos avaliados, com exceção de um SN colhido 24 horas após a indução da infecção. Não houve diferença significativa nas taxas de isolamento de Pasteurella multocida nos SN ou SNF, colhidos antes e após a indução da MPB. Contudo, esta bactéria passou a ser isolada mais freqüentemente após a indução da MPB, principalmente no SNF. Portanto, pode-se concluir que o exame microbiológico de SN e SNF é um teste auxiliar no diagnóstico da MPB. 
TERMOS DE INDEXAÇÃO: Flora bacteriana, vias aéreas anteriores, doenças respiratórias, bovinos, Mannheimia haemolytica.

\section{INTRODUÇÃO}

O complexo das doenças respiratórias bovinas é considerado um importante problema de sanidade animal, pois sua etiologia multifatorial, envolvendo fatores ambientais, condições de manejo e agentes infecciosos (Smith 2001, Radostits et al. 2002, Gagea et al. 2006), acarretam grandes perdas econômicas (Esslemont \& Kossaibati 1999, Virtala et al. 1999).

Segundo Magwood et al. (1969) a flora bacteriana das vias aéreas anteriores (VAA) de bezerros pode ser classificada em flora basal, amplamente distribuída na população de bezerros; flora suplementar, composta de espécies capazes de colonizar a mucosa nasal e a flora transitória, considerada originária do ambiente e que, em geral, é incapaz de colonizar a mucosa nasal.

Diferentes sorotipos de Mannheimia haemolytica são considerados comensais das VAA de bovinos sadios (Magwood et al. 1969, Woldehiwet et al. 1990), entretanto, em geral, são encontrados apenas em pequenas quantidades (Panciera \& Corstvet 1984, Catry et al. 2005) e por curtos períodos de tempo, na maioria das vezes inferiores a um dia (Frank et al. 1986). O sorotipo A1 é encontrado em menor quantidade que o A2, que é o sorotipo mais freqüentemente isolado das VAA de bovinos sadios (Frank \& Wessman 1978).

A quantidade de $M$. haemolytica A1 e Pasteurella multocida presente nos swabs nasais (SN) de bovinos com mannheimiose pulmonar aguda é bem mais elevada que aquela recuperada de animais sadios (JaramilloArango et al. 2008). M. haemolytica A1 se prolifera mais intensamente nas VAA de bovinos com mannheimiose pulmonar em comparação a animais sadios, tornando-os mais propensos a inalar maiores quantidades desta bactéria (Al-Ghamdi et al. 2000, Jaramillo-Arango et al. 2008).

$M$. haemolytica A1 não é apenas o agente infeccioso mais freqüentemente isolado de bovinos com mannheimiose pulmonar natural, mas a causa primária dos eventos patológicos que caracterizam esta doença clínica como uma broncopneumonia fibrinosa lobar aguda (Welsh et al. 2004, Gagea et al. 2006, Katsuda et al. 2007, Rice et al. 2007).

Quando se utilizam procedimentos onde M. haemolytica A1 é depositada diretamente nos pulmões, os fatores que causam estresses físicos ou infecciosos, que têm a função de suprimir os mecanismos de defesa das VAA, não são mais necessários para o desenvolvimento da enfermidade, o que torna estas técnicas mais vantajosas e úteis em pesquisas sobre a mannheimiose pneumônica bovina (MPB) (Fagliari 2003, Silva 2005, Lubbers et al. 2007, Srikumaran et al. 2007).

Experimentalmente a infusão intrabronquial de $5 \times 10^{9}$ unidades formadoras de colônia (UFCs) de M. haemolytica A1 produz quadro clínico agudo, com evolução para coma irreversível dentro de 24 horas após a inoculação
(Fagliari 2003). Contudo, McClenahan et al. (2000) e Silva (2005) reproduziram um quadro típico de mannheimiose pneumônica ao inocular, respectivamente, $1 \times 10^{9}$ e $1 \times 10^{10}$ UFCs via intrabronquial em bezerros.

Um modelo experimental de MPB foi utilizado neste trabalho com objetivo de avaliar a flora bacteriana das cavidades nasal e nasofaringeana dos bezerros antes e após a indução da MPB, bem como verificar a eficiência dos SN e SNF com fins de diagnóstico da doença.

\section{MATERIAL E MÉTODOS}

\section{Animais e grupos experimentais}

Utilizaram-se 28 bezerros da raça Holandesa, machos, com três a sete dias de idade, oriundos de fazendas de produção de leite da região de Botucatu/SP. A flora bacteriana nasal e nasofaringeana de todos os bezerros foi avaliada sete dias antes da inoculação com Mannheimia haemolytica A1 com o objetivo de identificar a flora basal. Em seguida, os animais foram divididos aleatoriamente em quatro grupos experimentais (G1 a G4), com sete bezerros cada, correspondendo à colheita da flora bacteriana nasal e nasofaringeana em quatro momentos diferentes após a inoculação, G1 (12h), G2 (24h), G3 (48h) e G4 (72h).

As medidas de biossegurança, os cuidados com as instalações e animais e os procedimentos experimentais foram previamente aprovados pela Câmara de Ética em Experimentação Animal da Faculdade de Medicina Veterinária e Zootecnia (FMVZ), Unesp-Botucatu.

\section{Seqüência experimental}

Durante os 27 dias da fase de adaptação, todos os bezerros foram mantidos em baias individuais e alimentados diariamente com quantidade de leite equivalente a $10 \%$ do peso vivo, distribuída em duas mamadas, água fresca, feno e ração comercial ad libitum. Neste período os bezerros foram submetidos a exames físicos diários, segundo Gonçalves et al. (2001).

No $28^{\circ}$ dia, sete dias antes da inoculação de M. haemolytica, foram colhidas amostras das secreções nasais e nasofaringeanas dos bezerros após anti-sepsia das narinas com álcool-iodado a $2 \%$, por meio de swabs protegidos por uma sonda-guia (Viana et al. 2007), com o objetivo de caracterizar a flora bacteriana das vias aéreas anteriores (VAA).

No $35^{\circ}$ dia, os animais foram inoculados com $1 \times 10^{9}$ UFC/ $\mathrm{mL}$ da cepa D153 de M. haemolytica A1.

Amostras das secreções nasais e nasofaringeanas dos bezerros de cada lote experimental foram colhidas para caracterizar a flora bacteriana das VAA dos animais de cada grupo, respectivamente, às 12, 24, 48 e 72 horas após a indução da infecção.

O material colhido antes e depois da inoculação foi acondicionado em tubos de ensaio contendo meio de transporte de Stuart e mantido sob refrigeração até o momento do processamento microbiológico.

\section{Exames bacteriológicos}

As amostras das secreções nasais e nasofaringeanas foram semeadas em placas de ágar-sangue enriquecidas com $5 \%$ de sangue desfibrinado de bovino e $6 \mu \mathrm{g}$ de vancomicina ${ }^{5}$ por mililitro de ágar, utilizadas como meio seletivo para os gêneros Mannheimia e Pasteurella; e em placas de ágar MacConkey

\footnotetext{
${ }^{5}$ Vancomicina CP, Lilly ${ }^{\circledR}$.
} 
que além de propiciar isolamentos bacterianos primários, permite a identificação e a diferenciação entre $M$. haemolytica e $P$. multocida, pois esta última espécie não cresce nesse meio de cultivo. Estas placas foram incubadas em estufa bacteriológica em aerobiose a $37^{\circ} \mathrm{C}$ por 48 horas, com observação do crescimento bacteriano a cada 24 horas. As colônias isoladas nas placas de ágar-sangue com vancomicina e suspeitas de pertencerem aos gêneros Mannheimia e Pasteurella foram submetidas a duas provas de triagem (citocromo-oxidase e catalase) e à coloração do esfregaço das colônias pela técnica de Gram (Carter \& Cole Júnior 1990).

Os isolados de Mannheimia e Pasteurella positivos nos testes de triagem e, no caso do gênero Mannheimia, com presença de hemólise no ágar sangue, foram submetidos às seguintes provas bioquímicas: fermentação dos açúcares glicose, lactose, maltose, sacarose e manitol. Além disso, os isolados de $M$. haemolytica, também foram submetidos às provas de trealose e arabinose; produção de urease e indol; redução da ornitina descarboxilase e de mobilidade (Carter \& Cole Júnior 1990).

Nestas provas bioquímicas, os isolados de $P$. multocida diferenciam-se daqueles de $M$. haemolytica por apresentarem provas de produção de indol e de redução da ornitina descarboxilase positivas e negativas para a fermentação de maltose e glicose (Carter \& Cole Júnior 1990).

Outros microorganismos isolados das secreções nasais e nasofaringeanas dos bezerros dos lotes experimentais como: Arcanobacterium pyogenes, Bacillus spp., Escherichia coli, Enterobacter spp., Micrococcus spp.; Moraxella spp.; Neisseria spp.; Proteus spp., Staphylococcus spp. e Streptococcus spp. foram identificados segundo suas características de cultivo, morfotintoriais e bioquímicas (Krieg \& Holt 1984).

\section{Preparo do inóculo de Mannheimia haemolytica A1 - CEPA D1536}

A cepa de Mannheimia haemolytica D153 liofilizada foi reidratada com $1 \mathrm{~mL}$ de água destilada estéril. Após a homogeneização, uma alíquota da suspensão foi transferida para $3 \mathrm{~mL}$ de caldo cérebro-coração $(\mathrm{BHI})$ estéril e incubada, sob aerobiose, por $24 \mathrm{~h}$ a $37^{\circ} \mathrm{C}$.

Logo após, o caldo BHI foi semeado em placas de ágar sangue enriquecidas com $5 \%$ sangue desfibrinado bovino e $6 \mu \mathrm{g}$ vancomicina, por mililitro de ágar, e em placas de ágar MacConkey, com o objetivo de comprovar a pureza da cepa D153, através das características morfotintoriais das colônias isoladas nas placas de ágar sangue, pelo crescimento no ágar MacConkey e pelos resultados das provas de triagem e bioquímicas, descritas anteriormente.

Posteriormente, um frasco com $200 \mathrm{~mL}$ de BHI estéril e préaquecido a $37^{\circ} \mathrm{C}$ foi inoculado com o máximo de colônias obtidas das placas de ágar sangue bovino e vancomicina onde o crescimento da cepa D153 de $M$. haemolytica A1 foi puro e exuberante, e incubado em aerobiose, a $37^{\circ} \mathrm{C}$, sob agitação constante de 150 ciclos $/$ minuto $^{7}$, durante sete horas. Em seguida, o inóculo foi conservado sob refrigeração para ser inoculado nos bezerros, em no máximo, uma hora após a preparação.

A concentração bacteriana foi estimada em torno de $1 \times 10^{9}$ UFC/mL (Weiss et al. 1991, McClenahan et al. 2000), com auxílio de espectrofotometria (1,0 de absorbância e $540 \mathrm{~nm}$ de comprimento de onda) e confirmada por contagem direta em esfregaço (Quinn et al. 1994).

\section{Inoculação de Mannheimia haemolytica A1}

Para realizar o procedimento de inoculação, os bezerros dos grupos experimentais foram contidos em decúbito lateral direito. Após tricotomia e anti-sepsia da pele da região cervical ventral anterior com álcool iodado a $5 \%$, foi realizado bloqueio anestésico local com cloridrato de lidocaína a $2 \%$.

Um cateter ${ }^{8}$ de $20,3 \mathrm{~cm}$ de comprimento e $2,03 \mathrm{~mm}$ de diâmetro foi introduzido no espaço entre dois anéis traqueais do terço anterior da traquéia, até atingir a região da carina. A seguir, as doses de 4 ou $5 \mathrm{~mL}$ do inóculo da cepa D153 de $M$. haemolytica $\mathrm{A} 1$ ( $1 \times 10^{9} \mathrm{UFC} / \mathrm{mL}$ ) foram infundidas nos bezerros.

Com o objetivo de promover o esvaziamento e a lavagem do cateter e de aumentar o volume do líquido infundido, de modo a se obter maior dispersão dos organismos de $M$. haemolytica A1 nas vias aéreas do pulmão direito, mais $5 \mathrm{~mL}$ de caldo $\mathrm{BHI}$ estéril foram infundidos pelo cateter, totalizando $10 \mathrm{~mL}$ de infusão por bezerro inoculado.

\section{Análise dos resultados}

Foi utilizado o Teste de Friedman para comparar as taxas de isolamento dos microorganismos, nos SN e SNF, antes e após a indução da MPB. Para comparar as freqüências de isolamento dos agentes bacterianos, nos SN e SNF, antes da inoculação da cepa D153 de M. haemolytica A1 e às 12, 24, 48 e 72 horas após a inoculação, respectivamente, nos grupos G1 a G4, utilizou-se o teste de Wilcoxon (Siegel 1975).

\section{RESULTADOS E DISCUSSÃO}

Os resultados dos cultivos microbiológicos das secreções dos swabs nasal (SN) e nasofaringeano (SNF) colhidas dos 28 bezerros, sete dias antes da inoculação da cepa D153 de M. haemolytica A1, para caracterizar a flora bacteriana dos bezerros normais estão apresentados no Quadro 1.

Antes da indução da MPB, verificou-se grande semeIhança entre a flora bacteriana de ambos os segmentos das vias aéreas anteriores (VAA), as cavidades nasal e

Quadro 1. Freqüência relativa dos microorganismos, isolados nos swabs nasal e nasofaringeano de bezerros sadios $(n=28)$

\begin{tabular}{lcc}
\hline Microorganismos & $\begin{array}{c}\text { Swab nasal } \\
\%\end{array}$ & $\begin{array}{c}\text { Swab nasofaringeano } \\
\%\end{array}$ \\
\hline Arcanobacterium pyogenes & 7,14 & 3,57 \\
Bacillus spp. & 60,71 & 42,86 \\
E. coli & 21,43 & 25,00 \\
Enterobacter cloacae & 3,57 & 3,57 \\
M. haemolytica A & 0.00 & 17,86 \\
Micrococcus spp. & 82,14 & 78,57 \\
Moraxella spp. & 3,57 & 0,00 \\
Neisseria spp. & 0,00 & 7,14 \\
P. multocida & 28,57 & 28,57 \\
Proteus spp. & 3,57 & 7,14 \\
Staphylococcus spp. & 35,71 & 32,14 \\
Streptococcus spp. & 42,86 & 35,71
\end{tabular}

\footnotetext{
${ }^{6}$ Cepa D153 de Mannheimia haemolytica A1, gentilmente cedida pelo Prof. Dr. Samuel K. Maheswaran do Departamento de Patobiologia, Universidade de Minnesota, EUA.

7 Orbital Shaker, Forma Scientific ${ }^{8}$.

${ }^{8}$ Cateter intravenoso I-CATH, Tecnobio ${ }^{\circledR}$.
} 
nasofaringeana, tanto em relação aos gêneros e espécies recuperados, quanto àqueles mais freqüentemente isolados. A ausência da $M$. haemolytica A1 nos SN e o seu isolamento em $17,86 \%$ (5/28) dos SNF pode ser considerado um diferencial nos perfis bacterianos dos SN e SNF obtidos antes da indução da MPB.

Segundo Magwood et al. (1969) e Woldehiwet et al. (1990), todos os agentes bacterianos recuperados das secreções dos SN e SNF antes da indução da MPB foram microorganismos comensais das VAA de bovinos sadios. Aplicando-se a classificação proposta por Woldehiwet et al. (1990), os agentes bacterianos isolados neste experimento poderiam ser divididos em: flora basal, P. multocida, M. haemolytica A, Neisseria spp., Micrococcus spp. e Streptococcus spp.; flora suplementar, Moraxella spp. e Arcanobacterium pyogenes; e flora transitória, Escherichia coli, Enterobacter cloacae, Bacillus spp. e Proteus spp.

A flora transitória, constituída por microorganismos da família Enterobacteriaceae e pelo gênero Bacillus, é considerada ubíqua (Murray et al. 1999) e indica contaminação durante o processo de colheita das secreções nasal

Quadro 2. Freqüências relativas de isolamento dos microorganismos, nos swabs nasal e nasofaringeano obtidos dos bezerros $(\mathrm{n}=\mathbf{2 8})$ antes e após a indução da mannheimiose pneumônica bovina (MPB)

\begin{tabular}{lccccc}
\hline \multirow{2}{*}{ Microorganismos } & \multicolumn{3}{c}{$S w a b$ nasal } \\
\cline { 2 - 3 } \cline { 5 - 6 } & $\begin{array}{c}\text { Antes } \\
\%\end{array}$ & $\begin{array}{c}\text { Após } \\
\%\end{array}$ & & $\begin{array}{c}\text { Swab nasofaringeano } \\
\%\end{array}$ & $\begin{array}{c}\text { Após } \\
\%\end{array}$ \\
\hline Arcanobacterium pyogenes & $7,14^{\mathrm{a}}$ & $0,00^{\mathrm{a}}$ & & $3,57^{\mathrm{a}}$ & $0,00^{\mathrm{a}}$ \\
Bacillus spp. & $60,71^{\mathrm{a}}$ & $42,86^{\mathrm{a}}$ & & $42,86^{\mathrm{a}}$ & $25,00^{\mathrm{a}}$ \\
E. coli & $21,43^{\mathrm{a}}$ & $10,71^{\mathrm{a}}$ & & $25,00^{\mathrm{a}}$ & $10,71^{\mathrm{a}}$ \\
Enterobacter aglomerans & $0,00^{\mathrm{a}}$ & $0,00^{\mathrm{a}}$ & $0,00^{\mathrm{a}}$ & $3,57^{\mathrm{a}}$ \\
Enterobacter cloacae & $3,57^{\mathrm{a}}$ & $0,00^{\mathrm{a}}$ & $3,57^{\mathrm{a}}$ & $0,00^{\mathrm{a}}$ \\
M. haemolytica A & $0,00^{\mathrm{a}^{*}}$ & $96,43^{\mathrm{b}}$ & $17,86^{\mathrm{a}}$ & $100,00^{\mathrm{b}}$ \\
Micrococcus spp. & $82,14^{\mathrm{a}}$ & $35,71^{\mathrm{a}}$ & $78,57^{\mathrm{a}}$ & $42,86^{\mathrm{a}}$ \\
Moraxella spp. & $3,57^{\mathrm{a}}$ & $0,00^{\mathrm{a}}$ & $0,00^{\mathrm{a}}$ & $0,00^{\mathrm{a}}$ \\
Neisseria spp. & $0,00^{\mathrm{a}}$ & $3,57^{\mathrm{a}}$ & $7,14^{\mathrm{a}}$ & $0,00^{\mathrm{a}}$ \\
P. multocida & $28,57^{\mathrm{a}}$ & $35,71^{\mathrm{a}}$ & $28,57^{\mathrm{a}}$ & $50,00^{\mathrm{a}}$ \\
Proteus spp. & $3,57^{\mathrm{a}}$ & $0,00^{\mathrm{a}}$ & $7,14^{\mathrm{a}}$ & $0,00^{\mathrm{a}}$ \\
Staphylococcus spp. & $35,71^{\mathrm{a}}$ & $28,57^{\mathrm{a}}$ & $32,14^{\mathrm{a}}$ & $7,14^{\mathrm{a}}$ \\
Streptococcus spp. & $42,86^{\mathrm{a}}$ & $21,43^{\mathrm{a}}$ & $35,71^{\mathrm{a}}$ & $14,29^{\mathrm{a}}$
\end{tabular}

* Letras minúsculas diferentes na linha, referente a cada tipo de swab, indicam diferenças estatísticas $(P<0,05)$, pelo teste de Friedman. e nasofaringeana. Contudo, é pouco isolada na ausência de doença respiratória característica (Murray et al. 1999).

Tanto nos SN quanto no SNF realizados antes da indução da MPB, Micrococcus spp. foram os agentes bacterianos mais freqüentemente isolados, respectivamente, $82,14 \%$ e $78,57 \%$, o que diferiu dos achados de Woldehiwet et al. (1990) que isolaram Staphylococcus spp. como bactérias mais freqüentes nas narinas de bezerros sadios.

Uma vez induzida a MPB, os perfis de colonização bacteriana das VAA dos bezerros deste experimento sofreram modificações importantes (Quadro 2).

A diminuição do número de espécies e gêneros, assim como das freqüências de isolamento de agentes bacterianos com exceção de $M$. haemolytica, tanto no SN como no SNF, após a indução da MPB não foi significativa $(P>0,05)$ em relação aos resultados encontrados antes da indução, mas foram mais pronunciados para os microrganismos que Woldehiwet et al. (1990) classificaram como componentes das floras suplementar e transitória das (VAA) dos bovinos, sugerindo que estas bactérias teriam perdido espaço para M. haemolytica A (Quadro 2).

Após a indução da MPB, os aumentos das freqüências de isolamento da $M$. haemolytica A1 foram significativos $(P<0,05)$ em todos os SN e SNF dos grupos $G 1$ a $G 4$, com exceção dos SNF do grupo G3 (Quadros 3 e 4).

$M$. haemolytica se tornou o agente bacteriano predominante tanto no SN quanto no SNF, sendo recuperada em taxas superiores àquelas obtidas para Micrococcus spp., Bacillus spp., Streptococcus spp. e Staphylococcus spp. que foram as bactérias mais freqüentemente isoladas, antes da indução da MPB.

Embora não tenha havido diferença significativa nas taxas de isolamento da $P$. multocida nos SN ou SNF, coIhidos antes e após a indução da MPB, esta bactéria, considerada integrante da flora basal das VAA de bezerros (Woldehiwet et al. 1990), passou a ser isolada mais freqüentemente após a indução da MPB, principalmente no SNF, o que estaria de acordo com as observações de Radostits et al. (2002) e Härtel et al. (2004).

Pode-se dizer que as freqüências de isolamento da $M$. haemolytica A1 nos SN e SNF colhidos antes e após a

Quadro 3. Freqüência absoluta dos principais microorganismos isolados no swab nasal dos bezerros antes e após 12 (G1), 24 (G2), 48 (G3) e 72 (G4) horas da indução da mannheimiose pneumônica bovina (MPB)

\begin{tabular}{|c|c|c|c|c|c|c|c|c|c|c|c|c|}
\hline \multirow[t]{2}{*}{ Microorganismos } & \multicolumn{3}{|c|}{$\mathrm{G} 1^{\mathrm{a}}$ (12 horas) } & \multicolumn{3}{|c|}{$\mathrm{G}^{\mathrm{a}}$ (24 horas) } & \multicolumn{3}{|c|}{$\mathrm{G}^{\mathrm{a}}$ (12horas) } & \multicolumn{3}{|c|}{ G4 $4^{\mathrm{a}}$ (72 horas) } \\
\hline & Antes & Após & P-value & Antes & Após & P-value & Antes & Após & P-value & Antes & Após & $P$-value \\
\hline Bacillus spp. & 6 & 4 & 0,361 & 3 & 3 & $>0,999$ & 6 & 2 & 0,068 & 2 & 3 & 0,361 \\
\hline E. coli & 2 & 1 & 0,593 & 0 & 0 & NR & 2 & 0 & 0,180 & 2 & 2 & $>0,999$ \\
\hline Micrococcus spp. & 5 & 2 & 0,109 & 6 & 2 & 0,068 & 6 & 4 & 0,180 & 6 & 2 & 0,068 \\
\hline P. multocida & 2 & 2 & $>0,999$ & 2 & 2 & $>0,999$ & 2 & 4 & 0,180 & 2 & 2 & NR \\
\hline Staphylococcus spp. & 2 & 2 & $>0,999$ & 2 & 1 & NR & 4 & 2 & 0,180 & 2 & 3 & 0,593 \\
\hline
\end{tabular}

a Animais por grupo $(n=7)$, ${ }^{2}$ Diferenças significativas $(P<0,05)$ pelo teste de Wilcoxon, NR = cálculo não realizado devido ao número insignificante de observações. 
Quadro 4. Freqüência absoluta dos principais microorganismos isolados no swab nasofaringeano dos bezerros antes e após 12 (G1), 24 (G2), 48 (G3) e 72 (G4) horas da indução da mannheimiose pneumônica bovina (MPB)

\begin{tabular}{|c|c|c|c|c|c|c|c|c|c|c|c|c|}
\hline \multirow[t]{2}{*}{ Microorganismos } & \multicolumn{3}{|c|}{$\mathrm{G} 1^{\mathrm{a}}$ (12 horas) } & \multicolumn{3}{|c|}{$\mathrm{G}^{\mathrm{a}}$ (24 horas) } & \multicolumn{3}{|c|}{ G3 $^{a}$ (12horas) } & \multicolumn{3}{|c|}{ G4a (72 horas) } \\
\hline & Antes & Após & P-value & Antes & Após & $\mathrm{P}$-value & Antes & Após & $\mathrm{P}$-value & Antes & Após & $\mathrm{P}$-value \\
\hline Bacillus spp. & 3 & 1 & 0,361 & 3 & 2 & 0,593 & 3 & 2 & 0,593 & 3 & 2 & NR \\
\hline E. coli & 2 & 1 & 0,593 & 0 & 0 & NR & 2 & 1 & 0,593 & 3 & 1 & 0,593 \\
\hline Micrococcus spp. & 3 & 1 & 0,361 & 6 & 5 & 0,593 & 7 & 3 & 0,068 & 6 & 3 & 0,361 \\
\hline P. multocida & 2 & 3 & 0,686 & 2 & 5 & 0,109 & 2 & 4 & 0,361 & 2 & 2 & $>0,999$ \\
\hline Staphylococcus spp. & 1 & 0 & NR & 2 & 1 & NR & 2 & 0 & 0,180 & 4 & 1 & 0,225 \\
\hline
\end{tabular}

a Animais por grupo $(n=7)$, ${ }^{*}$ Diferenças significativas $(P<0,05)$ pelo teste de Wilcoxon, NR = cálculo não realizado devido ao número insignificante de observações.

indução da MPB delinearam padrões típicos de colonização das VAA por esta bactéria, quando os bezerros estavam sadios e quando desenvolveram a MPB.

Antes da indução da MPB, M. haemolytica A não foi isolada nos SN e foi positiva em apenas 17,86\% (5/28) dos SNF. Provavelmente, isso ocorreu por que os sorotipos de $M$. haemolytica A estão presentes em pequenas quantidades nas VAA de bovinos sadios (Panciera \& Corstvet 1984, Catry et al. 2005).

A recuperação de $M$. haemolytica em cinco SNF e a sua ausência nos SN pode sinalizar que o tecido linfóide na nasofaringe, e não o epitélio da cavidade nasal seja o local mais intensamente colonizado por $M$. haemolytica A (Shoo et al. 1990).

Neste experimento, $M$. haemolytica A foi isolada em $27(96,43 \%)$ SN e $28(100,00 \%)$ SNF, após a indução da MPB (Quadro 2), com aumento significativo $(P<0,05)$ em relação aos animais antes da inoculação. Estes resultados reforçam os achados de Jaramillo-Arango et al. (2008), que relataram quantidades bem mais elevadas de $M$. haemolytica A1 em bovinos com MPB aguda, quando comparados aos animais sadios.

Provavelmente, a colonização maciça das (VAA) dos bezerros por $M$. haemolytica A após a indução da MPB, ocorreu devido à disseminação retrógrada da cepa D153 de $M$. haemolytica A1 inoculada nos pulmões dos bezerros para induzir a MPB ou por aerossóis expelidos a cada expiração. Por outro lado, observou-se à inspeção dos animais infectados, aumento dos linfonodos parotídeos e submandibulares levando a crer que uma das vias de disseminação de $M$. haemolytica nas VAA tenha sido o sistema linfático. Além disso, foram observados outros sinais da infecção que mostraram atividade respiratória anormal: hiperpnéia, dispnéia mista, aumento da intensidade dos ruídos respiratórios, presença de crepitação grossa e de sub-macicez pulmonar.

Como os isolados não foram sorotipados, é possível que outros sorotipos, além do $\mathrm{A} 1$, também estivessem presentes e em quantidades expressivas nas VAA dos bezerros após a indução da MPB. Além da cepa D153, é possível que cepas autóctones também tenham se multiplicado intensamente nas VAA dos bezerros deste experimento após a indução da MPB.

\section{CONCLUSÃO}

Nas condições em que este experimento foi realizado, conclui-se que após a indução da mannheimiose pneumônica bovina (MPB), Mannheimia haemolytica A foi a bactéria mais freqüentemente isolada das vias aéreas anteriores (VAA) dos bezerros, sendo a análise microbiológica de amostras obtidas por meio de swabs nasais (SN) e nasofaringeanos (SNF) um exame auxiliar importante no diagnóstico desta enfermidade.

Agradecimentos.- Os autores agradecem à Fundação de Amparo a Pesquisa do Estado de São Paulo (FAPESP) pelo financiamento deste experimento e ao Dr. Samuel K. Maheswaran, Departamento de Patobiologia da Universidade de Minnesota (EUA), pela doação das cepas de Mannheimia haemolytica.

\section{REFERÊNCIAS}

Al-Ghamdi G.M., Ames T.R., Baker J.C., Walker R., Chase C.C.L., Frank G.H. \& Maheswaran S.K. 2000. Serotyping of Mannheimia (Pasteurella) haemolytica isolates from the upper Midwest United States. J. Vet. Diagn. Invest. 12:576-578.

Carter G.R. \& Cole Junior J.R. 1990. Diagnostic procedures in veterinary bacteriology and mycology. Academic Press, San Diego, p.201-209.

Catry B., Haesebrouck F., Vliegher S.D., Feyen B., Vanrobaeys M., Opsomer G., Schawarz S. \& Kruif A.D. 2005. Variability in acquired resistance of Pasteurella and Mannheimia isolates from the nasopharynx of calves, with particular reference to different herd types. Microb. Drug. Resist. 11(4):387-394.

Esslemont R.J. \& Kossaibati M.A. 1999. The cost of respiratory diseases in dairy heifer calves. Bov. Pract. 33(2):174-178.

Fagliari J.J. 2003. Estudo clínico e laboratorial da pneumonia de bezerros induzida pela inoculação intrabronquial de Mannheimia haemolytica. Arq. Bras. Med. Vet. Zootec. 55(1):8-14.

Frank G.H. \& Wessman G.E. 1978. Rapid plate agglutination procedure for serotyping Pasteurella haemolytica. J. Clin. Microbiol. 7:142-145.

Frank G.H., Briggs R.E. \& Gillette K.G. 1986. Colonization of the nasal passages of calves with Pasteurella haemolytica serotype 1 and regeneration of colonization after experimentally induced viral infection of the respiratory tract. Am. J. Vet. Res. 47(8):1704-1707.

Gagea M.I., Bateman K.G., van Dreumel T., McEwen B.J., Carman S., Archambault M., Shanahan R.A. \& Caswell J.L. 2006. Diseases and pathogens associated with mortality in Ontario beef feedlots. J. Vet. Diagn. Invest. 18:18-28.

Gonçalves R.C., Kuchembuck M.R.G., Curi P.R., Chiacchio S.B., Almeida C.T. \& Borges A.S. 2001. Diferenciação clínica da broncopneumonia moderada e grave em bezerros. Ciência Rural 31:263-269. 
Härtel H., Nikunen S., Neuvonen E., Tanskanen R., Kivelä S.L., Aho P., Soveri T. \& Saloniemi H. 2004. Viral and bacterial pathogens in bovine respiratory disease in Finland. Acta Vet. Scand. 45:193-200.

Jaramillo-Arango C.J., Hernández-Castro R., Suárez-Güemes F., Martínez-Maya J.J., Aguilar-Romero F., Jaramillo-Meza L. \& Trigo F.J. 2008. Characterization of Mannheimia spp. strains isolated from bovine nasal exudate and factors associated to isolates, in dairy farms in the Central Valley of Mexico. Res. Vet. Sci. 84:7-13.

Katsuda K., Kamiyama M., Kohmoto M., Kawashima K., Tsunemitsu H. \& Eguchi M. 2007. Serotyping of Mannheimia haemolytica isolates from bovine pneumonia: 1987-2006. Vet. J. online, fevereiro, 2008. Disponível: http:// www.elsevier.com/locate/tvjl Acesso em 12 fev. 2008.

Krieg N.R. \& Holt J.G. 1984. Bergey's Manual of Systematic Bacteriology. Williams and Wilkins, London, p.984.

Lubbers B.V., Apley M.D., Coetzee J.F., Mosier D.A., Biller D.S., Mason D.E. \& Henao-Guerrero P.N. 2007. Use of computed tomography to evaluate pathologic changes in the lungs of calves with experimentally induced respiratory tract disease. Am. J. Vet. Res. 68(11):1259-1264.

Magwood S.E., Barnum D.A. \& Thomson R.G. 1969. Nasal bacterial flora of calves in healthy and in pneumonia-prone herds. Can. J. Comp. Med. 33(4):237-243.

McClenahan D.J., Fagliari J.J., Evanson O.A. \& Weiss D.J. 2000. Role of platelet-activating factor in alveolar septal injury associated with experimentally induced pneumonic pasteurellosis in calves. Am. J. Vet. Res. 61(3):248-254.

Murray P.R., Baron E.J., Pfaller M., Tenover F.C. \& Yolken R.H. 1999. Manual of Clinical Microbiology. American Society for Microbiology, Washington, p.567.

Panciera R.J. \& Corstvet R.E. 1984. Bovine pneumonic pasteurellosis: model for Pasteurella haemolytica- and Pasteurella multocida-induced pneumonia in cattle. Am. J. Vet. Res. 45:2532-2537.

Quinn P.J., Carter M.E., Markey B. \& Carter G.R. 1994. Clinical Veterinary Microbiology. Wolfe, London, p.648.

Radostits O.M., Gay C.C., Blood D.C. \& Hinchcliff K.W. 2002. Clínica Veterinária: um tratado de doenças de bovinos, ovinos, suínos, caprinos e eqüinos. Guanabara Koogan, Rio de Janeiro, p.1737.
Rice J.A., Carrasco-Medina L., Hodgins D.C., Shewen P.E. 2007. Mannheimia haemolytica and bovine respiratory disease. Anim. Health Res. Rev. 8(2):117-128.

Silva D.P.G. 2005. Avaliação da técnica de biopsia pulmonar transtorácica em bezerros clinicamente sadios e com broncopneumonia induzida experimentalmente. Dissertação de Mestrado em Medicina Veterinária, Faculdade de Medicina Veterinária e Zootecnia, Unesp, Botucatu, SP. 75p.

Shoo M.K., Wiseman A., Gibbs H.A., Al-Hendi A.B. \& Selman I.E. 1990. Distribution of Pasteurella haemolytica in the respiratory tracts of carrier calves and those subsequently infected experimentally with Dyctiocaulus viviparus. Res. Vet. Sci. 48:383-385.

Siegel S. 1975. Nonparametric Statistics for the Behavioral Sciences. McGraw Hill Book Company, New York, p.321.

Smith B. 2001. Large Animal Internal Medicine. Mosby, Philadelphia, p.2112.

Srikumaran S., Kelling C.L. \& Ambagala A. 2007. Immune evasion by pathogens of bovine respiratory disease complex. Anim. Health Res. Rev. 8(2):215-229.

Viana L., Gonçalves R.C., Oliveira Filho J.P., Paes A.C. \& Amorim R.M. 2007. Ocorrência de Mannheimia haemolytica e de Pasteurella multocida em ovinos sadios e com enfermidades respiratórias. Arq. Bras. Med. Vet. Zootec. 59:1579-1582.

Virtala A.M.K., Gröhn Y.T., Mechor G.D. \& Erb H.N. 1999. The effect of maternally derived immunoglobulin $\mathrm{G}$ on the risk of respiratory disease in heifers during the first 3 months of life. Prev. Vet. Med. 39:25-37.

Weiss D.J., Bauer M.C., Whiteley L.O., Maheswaran S.K. \& Ames T.R. 1991. Changes in blood and bronchoalveolar lavage fluid components in calves with experimentally induced pneumonic pasteurellosis. Am. J. Vet. Res. 52(2):337-344.

Welsh R.D., Dye L.B., Payton M.E. \& Confer A.W. 2004. Isolation and antimicrobial susceptibilities of bacterial pathogens from bovine pneumonia: 1994-2002. J. Vet. Diagn. Invest. 16:426-431.

Woldehiwet Z., Mamache B. \& Rowan T.G. 1990. The effects of age, environmental temperature and relative humidity on the bacterial flora of the tract respiratory upper in calves. Brit. Vet. J. 146:211-218. 